\title{
RANDOM NUMBER GENERATOR UNTUK BOBOT METODE CONJUGATE GRADIENT NEURAL NETWORK
}

\author{
${ }^{1}$ Yudistira Arya Sapoetra, ${ }^{2}$ Azwar Riza Habibi, dan ${ }^{3}$ Lukman Hakim \\ 1,2,3 Teknik Informatika, STMIK ASIA Malang \\ ${ }^{1}$ yuditstiraarya@gmail.com, ${ }^{2}$ riza.bj@gmail.com, ${ }^{3}$ bledeklukman@gmail.com
}

\begin{abstract}
This research develosp theory of $N N$ (neural network) by using $C G$ (conjugate gradient) to speed up the process of convergence on a network of NN. CG algorithm is an iterative algorithm to solve simultaneous linear equations on a large scale and it is used to optimize the process of the network on backpropagation. In the process a Neural netwok doing random weighting on the weight of $v$ and $w$ and this weight wil have an effect on the speed of convergence of an algorithm for $N N$ by the method of CG. Furthermore, generating the random numbers to take a sample as generator in this research of neural network by using uniform distribution $(0,1)$ methods. Therefore, the aims of this research is to improve the convergence on $N N$ weighting using numbers which are generated randomly by generator and the will be corrected with the CG method.
\end{abstract}

Keywords: neural network, backpropagation, weighting, conjugate gradient

\section{PENDAHULUAN}

Secara prinsip $\quad N N$ ini dibangkitkan oleh serangkaian input data yang masing-masing menggambarkan keluaran neuron yang lain. Menurut Sheikhan (2012:1186) Setiap masukan dikalikan dengan suatu faktor pembobot tertentu dan kemudian semua masukan terbobot itu dijumlahkan untuk menentukan tingkat aktivitas suatu neuron. Pembobotan dinyatakan berupa elemen-elemen matriks bobot $(w)$ dengan dimensi matriks adalah $m$ baris dan $n$ kolom, di mana $m$ merupakan jumlah masukan dan $n$ menunjukkan jumlah neuron. Misalnya, pembobot dengan yang menghubungkan masukan keempat ke neuron ketiga dinyatakan dengan $w$. AlBayati (2009:849) mengembangkan metode NN dengan mengabungkan conjugate gradietn. Metode conjugate gradient merupakan salah satu metode yang digunakan untuk memperoleh nilai optimum suatu fungsi. Pada umumnya metode conjugate gradient dapat digunakan untuk menyelesaikan permasalahan optimasi linear maupun optimasi nonlinear. Dari hasil Nawi (2008:905), penulis mengembangkan conjugate gradient neural network (CGNN) dengan menambahkan bobot yang menggunakan random number generator berbasis distribusi uniform.

\section{Rahman}

(2013:E-106), mengembangkan random sampling dengan menggunakan distribusi hipergeometri, dalam metode sampling, terdapat tiga macam kesalahan yang mungkin terjadi, yaitu random error, systematic error dan illegitimate error. Random error adalah kesalahan dalam menentukan keacakan, sehingga distribusi 
Random Number Generator Untuk Bobot Metode Conjugate Gradient Neural Network Yudistira Arya Sapoetra, Azwar Riza Habibi, Lukman Hakim

sampel kurang sesuai dengan distribusi populasi. Systematic error adalah kesalahan metode pengambilan sampel, sehingga sampel masih kurang atau terkumpul di sebagian populasi. Illegitimate error adalah kesalahan akibat kelalaian saat sampling, misalnya mengambil sampel dari bukan populasinya. Kesalahan sampling memberikan hasil bias dan tidak valid, sehingga tidak dapat mewakili populasi untuk digunakan analisa lebih lanjut. Salah satu metode sampling yang banyak digunakan adalah simple random sampling yang mengasumsikan beberapa hal. Diasumsikan populasi telah diketahui secara keseluruhan. Sampel diasumsikan ditarik secara acak dari populasi. Masingmasing anggota populasi diasumsikan mempunyai peluang sama terpilih sebagai sampel. Diasumsikan alat pengacakan atau randomisasi dapat mendukung dalam proses melakukan trial saat sampling, Levy (2009:34).

Peper ini menggembangkan CGNN (conjugate gradient neural network) dengan menggunakan random number generator distribusi uniform $(0,1)$. Random number ini digunakan untuk meminimumkan error pada bilangan acak yang terdapat pada pembobotan $v$ dan $w$, sehingga hasil dari pembangkitan random number ini mempercepat konvergen dalam pelatihan jaringan.

\section{KAJIAN TEORI}

Data yang digunakan adalah data curah hujan untuk training diambil dari BPS (Badan Pusat Statistik). Parameter yang digunakan untuk CGNN random number generator dapat dilihiat pada tabel 1 .

Tabel 1 Parameter yang digunakan CGNN random number generator

\begin{tabular}{|c|c|c|}
\hline No & Parameter & Nilai Parameter \\
\hline 1 & Hidden layer & 12 note \\
\hline 2 & Error Toleransi & $10^{-6}$ \\
\hline 3 & Learning rate & 0.08 \\
\hline
\end{tabular}

2.1. Conjugate Gradient

Merode conjugate gradient pertamakali digunakan untuk menyeleseikan persamaan linier, metode ini efektif untuk sistem persamaan linier dengan ukuran besar, yaitu:

$$
A x=b
$$

Dengan $x$ adalah fektor yang tidak diketahui, $b$ adalah vektor yang diketahui dan $A$ adalah matriks simetris. Metode $C G$ dapat juga digunakan untuk menyelseikan suatu sistem persamaan linier walaupun $A$ bukan matrik simetris. Metode conjugate gradien ini digunakan untuk mecari arah pencarian arah dengan metode penurunan

$$
p_{0}=-g_{0}
$$

Dari pencarian arah tersebut maka perubahan gradient untuk $k+1$, yaitu:

$$
\nabla x_{k}=\left(x_{k+1}-x_{k}\right)=a_{k} p_{k}
$$


Dengan $a_{k}$ dipilh untuk meminimumkan fungsi sepanjang arah pencarian, untuk fungsi kuadratis dapat digunakan

$$
a_{k}=-\frac{\left.\nabla F(x)^{T}\right|_{x=x} p_{k}}{\left.p_{k}^{t} \nabla F(x)\right|_{x=x} p_{k}}=-\frac{g_{k}^{T} p_{k}}{p_{k}^{T} A_{k} p_{k}}
$$

Selanjutnya pilih arah pencarian dengan menggunakan

$$
p_{k}=-g_{k}+\beta_{k} p_{k-1}
$$

Dengan $\beta_{k}$ dapat dihitung dengan metode yang memberikan hasil yang sama untuk fungsi kuadratis.

\subsection{Neural \\ Network \\ Backpropagation}

Jaringan backpropagation adalah jaringan lapis jamak yang dilatih dengan algoritma perambatan galat balik (back Error Propagation) atau sering disebut backpropagation. Tujuan jaringan ini adalah untuk melatih jaringan agar mampu menanggapi secara benar pola pola masukan yang digunakan saat pelatihan dan mampu memberikan tanggapan yang baik untuk pola pola yang mirip tetapi tidak sama dengan polapola pelatihan, Kumar(2014:56).

Pelatihan jaringan backpropagation terdiri dari 3 tahap, tahap pertama adalah langkah maju (feedforwad) untuk input pola pelatihan, kedua adalah perhitungan dan perambatan balik (backpropagation) dari galat yang bersangkutan dan tahap ketiga adalah penyesuaian bobot. Model jaringan backpropagation sebagai berikut:

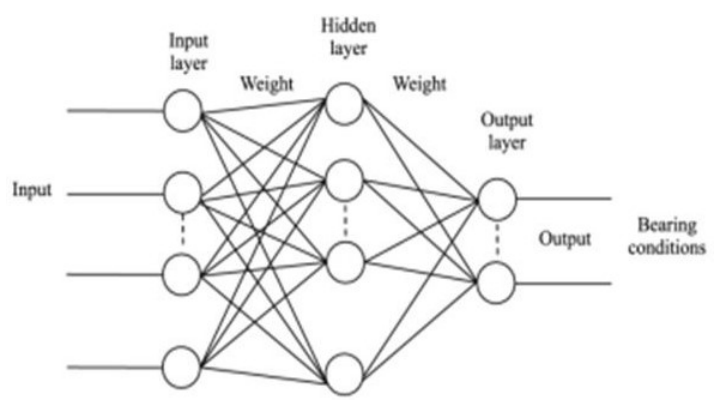

Gambar 1 Jaringan Backpropagation

\subsection{Random Number generator}

Langkah-langkah dari algoritma random number dengan menggunakan pendekata inverse-transformasi random generator berbasis distribusi uniform $(0,1)$ sebagai berikut, Thompson (1992:145):

1. Menentukan jumlah populasi $N p$, Menentukan kejadian suskses $k$, dalam populasi berdasarkan ukuran sampel $N s$.

$$
N=N p, k=N s
$$

2. Menentukan banyaknya grup dan ukuran seragam tiap grup n, berdasarkan jumlah populasi $N p$.

$$
n=\frac{N p}{\text { grup }}
$$

3. Memperoleh bilangan acak, $U$ antara 0 dan 1, yang diperoleh dari pseudo random number generator distribusi Uniform $(0,1)$

$$
U \approx \text { uniform }(0,1)
$$

4. Membangkitkan variabel acak $X$, dengan cara memasukan nilai $U$ ke dalam inverse dari fungsi distribusi kumulatif $F^{-1}(U)$. Karena $X$ adalah 
Random Number Generator Untuk Bobot Metode Conjugate Gradient Neural Network Yudistira Arya Sapoetra, Azwar Riza Habibi, Lukman Hakim

bilangan bulat dengan $X \geq 1$, maka nilai $X$ diperoleh dari pembulatan keatas

$$
X=F^{-1}(U), 1 \leq X \leq k
$$

5. Menentukan banyaknya sampel ke- $i$

$$
S_{i}=X
$$

6. Hitung banyaknya sampel

$$
N S=\sum_{i=1}^{g r u b} S_{i}
$$

\section{METODE PENELITIAN}

CGNN dengan menggunakan random number generator dengan tujuan untuk meminimumkan penggunakan nilai random pada bobot yang digunakan untuk membangkitkan bobot pada neural network. Langkah-langkah conjugate gradient neural network dengan random number generator untuk menyelesaikan data training dapat dijelaskan sebagai berikut:

Langkah 1 : Menginputkan data training. Langkah 2 : Menginisialisasi semua bobot yang digunakan sebagai nilai awal metode feedforward.

Langkah 3 : Random generator berbasis distribusi uniform $(0,1)$, $U_{i j}=v_{i j}, U_{j k}=w_{j k}$

\section{Tahap Feedforward}

Langkah 4 : Tiap unit masukan $\left(X_{i}\right)$ menerima sinyal input dan mengirim ssinyal ke semua unit pada lapisan berikutnya.
Langkah 5 : tiap unit tersembunyi $\left(z_{j}\right)$ menjumlah sinyal input bobot $z_{-}$in ${ }_{j} \quad$ kemudian dikeluarkan dengan menggunakan fungsi aktifasi $z_{j}=f\left(z_{-} i n_{j}\right)$

Langkah 6 : tiap unit keluaran $\left(y_{k}\right)$ menjumlahkan sinyal masukan bobot $y_{-} i n_{k}$ kemudian dikeluarkan dengan menggunakan fungsi aktifasi $y_{k}=f\left(y_{-} i n_{k}\right)$

\section{Tahapan Backpropagation}

Langkah 7 : tiap unit keluaran $\left(y_{k}\right)$ menerima pola target yang sesuai dengan pola masuk pelatihan, hitung galat $\delta_{k}=\left(t_{k}-y_{k}\right) f^{\prime}\left(y_{-} i n_{k}\right)$, hitung gradien pada lapisan output $G 2_{j k}=-\delta_{k} z_{j}$, kirim $\delta_{k}$ pada lapis sebelumnya.

Langkah 8 : tiap unit tersembunyi $\left(z_{j}\right)$ menjumlahkan delta masukannya $\delta_{-} i n_{j}$ kalikan dengan turunan aktifasinya $\delta_{k}=\delta_{-} i n_{j} f^{\prime}\left(z_{-} i n_{j}\right)$ hitung gradient pada lapisan tersembunyi $G 1_{i j}=-\delta_{j} x_{i}$

Langkah 9 : tiap unit keluaran $\left(y_{k}\right)$ menghitung rata-rata gradien $\nabla G 2_{j k}=\frac{\sum_{j=0, k=0}^{n, m} G 2}{N}$ 
tiap unit tersembunyi $\left(z_{j}\right)$

menghitung

rata-rata

gradien $\nabla G 1_{i j}=\frac{\sum_{i=0, j=0}^{p, n} G 1}{N}, N$

adalah jumlah pola pelatihan.

Langkah 10 : tentukan $q=1$

Langkah 11 : Hitung arah pencarian lapis tersembunyi $p 1_{i j}=-\nabla G 1_{i j}$, hitung arah pencarian lapis tersembunyi $p 2_{i j}=-\nabla G 2_{i j}$

Langkah 12 : hitung $a_{1}$ pada lapis tersembunyi dan $a_{2}$ pada lapis keluaran dengan metode golden search dengan fungsi yang diminimalkan

$f(w)=\frac{1}{2 N} \sum_{n} \sum_{t}\left(t_{k}-y_{k}(w)\right)^{2}$

Langkah 13 : tiap unit keluaran $\left(y_{k}\right)$ menyesuaikan bobot $w_{j k}($ baru $)=w_{j k}($ lama $)+\left(a_{2}\right)\left(p 2_{j k}\right)$ tiap unit keluaran $\left(z_{j}\right)$ menyesuaikan bobot $v_{i j}($ baru $)=v_{i j}(\operatorname{lama})+\left(a_{1}\right)\left(p 1_{i j}\right)$

Langkah 14 : kondisi berhenti jika galat $<$ toleransi, dan jika galat $\geq$ toleransi lanjutkan ke langkah 14

Langkah 15 : Untuk masing-masing pasangan data pelatihan, ulangi langkah 2 hingga 13 sampai kondisi galat terpenuhi

\section{HASIL DAN PEMBAHASAN}

Data yang digunakan untuk data training diperoleh dari Badan Pusat Statistika (BPS). Pada DATA 2 menggunakan jumlah curah hujan sebanyak 125 Stasiun BMKG (Badan Meteorologi, Klimatologi dan Geofisika) di Indonesia pada tahun 2003.

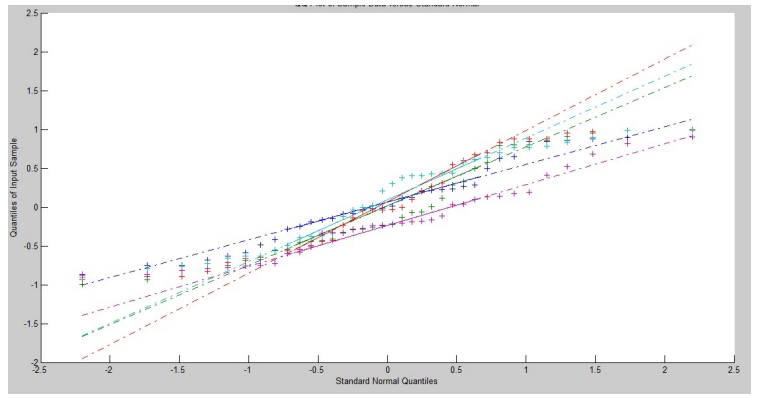

Gambar 2 Persebaran bobot tanpa random Number Genetator Parameter yang digunakan pada algoritma CGNN-Random Number Genetator maupun metode yang digunakan untuk pembanding dapat )dilihat pada Tabel 1. Pada peper ini menggunakan populasi sebanyak jumlah hidden layer pada $\mathrm{NN}$ dan maksimum iterasi (maxiter) $=100$ untuk menyimpan waktu komputasi. Parameter tersebut digunakan untuk membandingkan tingkat keakuratan dan minimum error. 
Random Number Generator Untuk Bobot Metode Conjugate Gradient Neural Network Yudistira Arya Sapoetra, Azwar Riza Habibi, Lukman Hakim

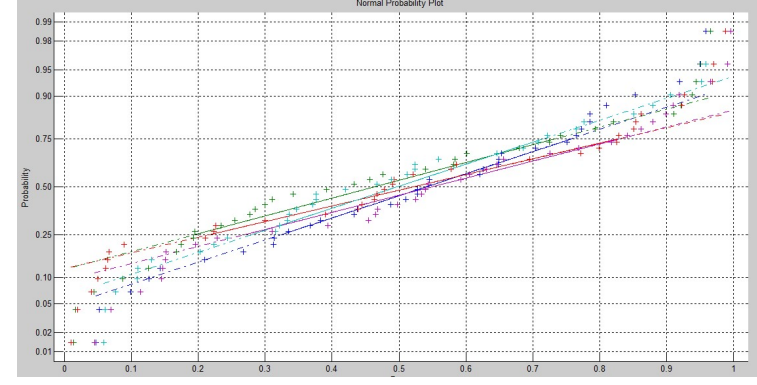

Gambar 3 Persebaran data random Number Genetator

Setelah 20 kali running program pada algoritma CGNN, didapatkan nilai bobot dengan nilai random dan dilihat persebaran dari data random tersebut menghasilkan gambar 2. Persebaran pada gambar 2 menunjukan bahwa persebaran data semakin menjauhi titik normal sehingga mempengaruhi hasil dari pelatihan pada CGNN

Dengan menggunakan Random Number Generator persebaran data menjadi lebih mendekati garis normal, sehingga dapat memperbaiki bobot pada CGNN

Table 2 Hasil Perbandingan pada metode CGNN

\begin{tabular}{ccccc}
\hline No & Metode & MSE & Waktu (s) & Itrasi ke- \\
\hline 1 & CG-NN & 0,6616 & 4.295 & 6 \\
2 & $\begin{array}{c}\text { CG-NN Random } \\
\text { number generator }\end{array}$ & 0.1540 & 4,345 & 3 \\
\hline
\end{tabular}

Dari hasil perbandingan antara CGNN dan CGNN Random number generator menghasilkan kecepatan dalam mendapatkan hasil yang terbaik dari jumlah itrasi untuk mendapatkan hasil konvergen dan MSE untuk kedua algoritma

\section{KESIMPULAN}

Metode CGNN Random number generator mampu mendapatkan bobot yang baik untuk mendapatkan hasil konvergen dari pelatihan jaringan $N N$. Pembobotan awal dibangkitkan dengan menggunakan random number generator kemudian bobot dilakukan perbaikan dengan menggunakan conjugate gradient untuk mendapatkan bobot yang optimal. Hal ini dikarenakan Random number generator dapat memberikan persebaran dari nilai bobot yang merata, sehingga pembobotan dari random number generator dapat mempercepat proses itrasi dan error yang lebih kecil.

\section{DAFTAR PUSTAKA}

Al-Bayati, A.Y., N.A. Sulaiman, dan G.W. Sadiq. 2009. A Modified Conjugate Gradient Formula for Backpropagation Neural Network Algorithm. Jurnal of Cumputer Science. 5. 849-856.

Kumar, D.A., dan S. Murugan. 2014. Performance Analysis of MLPFF Neural Network Back propagatioan raining Algorithm for Time Series Data. World Congress on Computing and Communication Technologies. 978. 114-119. 
Levy, P.S. \& Lemeshow, S.1999. Sampling of Populations: Methods and Applications. US: John Wiley \& Sons Nawi, N.M., M.R. Ransing, dan R.S. Ransing. 2008. An Improved Learning Algorithm based on the conjugate Gradien Method for Back Propagation Neural Networks. World Academy of Science, Engineering and Technology. 20. 905-908

Rahman, Arif. 2013. Pengacakan Random Sampling Dengan Pendekatan Inverse-Transform Random Variate Generator Berbasis Distribusi
Hipergeometrik. Prosiding Seminar Nasional Teknoin. Vol 4 2013. E-106E-111

Sheikhan, M., dan N. Mohammadi. 2012. Time Series Prediction Using PSOOptimized Neural Network and Hybrid Feature Selection Algoritm for IEEE Load Data. Neural Comput \& Applic. 23. 1185-1194.

Thompson, S.K..1992. Sampling. UB: John Wiley \& Sons 